\title{
Determination of the Scale of Damage in the Wastewater Tunnels Due to Earthquake: A Case Study
}

\author{
Turgay Çoşgun ${ }^{1}$, Çağatay Turgut ${ }^{2}$, Baris Sayin ${ }^{3}$ and Ahmet Çoşgun ${ }^{4}$ \\ 1. Department of Civil Engineering, Istanbul University, Istanbul 34320, Turkey \\ 2. Institute of Science, Istanbul University, Istanbul 34452, Turkey \\ 3. Department of Construction and Technical Affairs, Istanbul University, Istanbul 34116, Turkey \\ 4. Vocational School of Technical Sciences, Akdeniz University, Antalya 07058, Turkey
}

\begin{abstract}
The pre-determination of the effect of earthquake in subsurface structures is gaining importance increasingly. One of the main factors in determination of the damages due to earthquakes in subsurface structures, especially tunnels are horizontal acceleration value. The aim of the study is to put forward the scale of damage due to earthquake in a wastewater tunnel in Istanbul, the most populated city of Turkey, under construction. Possible damage caused by earthquake will be determined by utilizing the information about the route of the wastewater tunnel analyzed in the study.
\end{abstract}

Key words: Subsurface structures, tunnels, earthquake damage scale.

\section{Introduction}

All the structures used to maintain the life of humankind are defined as infrastructures vital for places where all necessities for societies such as water, energy, fuel and communication are produced, transported and utilized [1]. Damages occurring in infrastructures during an earthquake extremely affect the daily life. Apart from the significant economic losses, such cases may put the public health at risk. For this reason, in underground structures, predetermination of the possible damages of the earthquakes becomes important increasingly. Horizontal ground acceleration value is one of the main factors in determination of the damages in the underground structures especially damages in tunnels caused by earthquakes.

When the damages occurring in the underground structures are examined, it can be seen that they are mainly caused by landslides and faulting [1]. The earthquake, by itself, rarely causes damages in these

Corresponding author: Baris Sayin, Ph.D., research fields: earthquake and reinforced concrete structures. E-mail: barsayin@istanbul.edu.tr. structures. Tunnel can be blocked by damages, which are formed in the frames of the tunnel as a result of the land sliding. The main points in the tunnels at which the damages are concentrated are crossroads, parts at which direction and shape changes exist and parts at which the construction material or the type of the ground varies. In tunnels with inner lining, the damages are typically limited as cracks on the lining. In the study conducted by Owen and Scholl for tunnels [2], if the ground acceleration is lower than $0.4 \mathrm{~g}$, then the damage in the hard rock tunnels is very limited. Up to $0.19 \mathrm{~g}$, damage did not occur in any lined or unlined tunnel. Between $0.19 \mathrm{~g}$ and $0.4 \mathrm{~g}$, small cracks appear and some bricks or stones fell off from the lining. Collapse of the tunnel was not observed in the tunnels up to $0.5 \mathrm{~g}$ values. It was stated that serious damages in the inner lining and tunnel area are the results of the low quality inner lining and inferior ground conditions. The seismic dangers that could be observed in the wastewater tunnels can be grouped as temporary and permanent landslides that may occur in the ground. While the temporary ones through seismic waves, permanent 
landslides can be formed due to different reasons such as ground faulting, liquefaction, landslide and settlements [3].

Under the seismic motions, underground structures demonstrate three types of deformation, namely axial tension and compression, longitudinal bending and rounding/bending [4]. The axial deformations in the underground structures form as a result of the compressive and tensile stresses, which are originating from parallel motions in the axis of the structure, caused by seismic waves. Longitudinal bending, on the other hand, forms as a result of the perpendicular particle motions, originated by seismic waves, along the axis of the structure. It was depicted that in rounding/bending, shear waves propagate perpendicular or near perpendicular to the axis of the tunnel and this yields bending of the cross section of the tunnel [5].

In the study, the degree of the damage, that could occur in a wastewater tunnel, which is being built in Istanbul, the most populated city of Turkey, is presented. Within this scope, by using the information about the route at which the tunnel will pass through (geotechnical report, waste water application plan, lithological cross-section, cross-section of the RC and its properties), it was examined if a damage would occur as a result of an earthquake.

\section{Damages Occur in the Infrastructures as a Result of Earthquakes}

Yüzügüllü and Uğurlu [6] conducted a study to determine the damage levels of the wastewater and water supply networks present in Istanbul
Metropolitan district. The results obtained in the study are given in Table 1. The total numbers of pipe break in the wastewater network, including all other counties, were given as 1959. It was stated that in 940 of them damages occurred due to liquefaction.

\section{The Geology of the Study Area}

In the study area including close neighborhood, "Basic Mass" formations belonging to Paleozoic Era, i.e., 500 to 300 million years ago, are present. This mass consists of different formations from Ordovician, Silurian, Devonian and Lower Carboniferous Periods as well as from two granodioritic massive grown into these formations. It covers the large areas on the coastal region of Marmara Sea, both sides of the Bosphorus, the Islands of Istanbul and Gebze in Kocaeli Provience [7]. Generally in the research area, the regions called as floor (natural, alluvium, marine sedimentary) or main rock with high and low amount of cracks, fractures, faults and folds cut by limestone, shale, mudstone-limestone, andesite and diabase dikes were passed on the valley-bay passages close to the sea. The geomechanical properties of the rock used in constructed tunnel and the tunnel route are given in Table 2 and Fig. 1, respectively.

The final cross and longitudinal sections of the wastewater tunnel, which will be opened through the studied route is presented in Figs. 2 and 3.

\subsection{Underground Water Observations}

Table 3 presents the depths of underground water according to the underground water observations

Table 1 The total numbers of pipe break in the wastewater network [6].

\begin{tabular}{lllll}
\hline County & Location of damage & Number of damage & Cause of damage & Level of damage \\
\hline Bakırköy & Wastewater outline & 216 & Pipe fracture & Heavy \\
Pendik & Wastewater outline & 123 & Pipe fracture & Normal \\
Kadıköy & Wastewater outline & 178 & Pipe fracture & Normal \\
Kartal & Wastewater outline & 163 & Pipe fracture & Normal \\
Tuzla & Wastewater outline & 148 & Pipe fracture & Normal \\
Adalar & Wastewater outline & - & - & Normal \\
Avcılar-Beykoz & Wastewater outline & - & - & Heavy \\
\hline
\end{tabular}


Table 2 Geomechanic properties of the rock units [7].

\begin{tabular}{|c|c|c|c|c|c|c|}
\hline Units & Density $\left(\mathrm{kN} / \mathrm{m}^{3}\right)$ & Porosity & $\begin{array}{l}\text { Non-confined compression } \\
\text { test }(\mathrm{MPa})\end{array}$ & $\begin{array}{l}\text { Young's modulus } \\
(\mathrm{GPa})\end{array}$ & Poisson ratio & $\begin{array}{l}\text { Tensile stress } \\
(\mathrm{MPa})\end{array}$ \\
\hline Limestone & $25.91-26.45$ & $0.89-2.73$ & $28-40$ & $42-65$ & $0.30-0.31$ & $2.6-5.20$ \\
\hline Andesite & & & 4.60 & 20 & 0.22 & $1.32-5.39$ \\
\hline
\end{tabular}

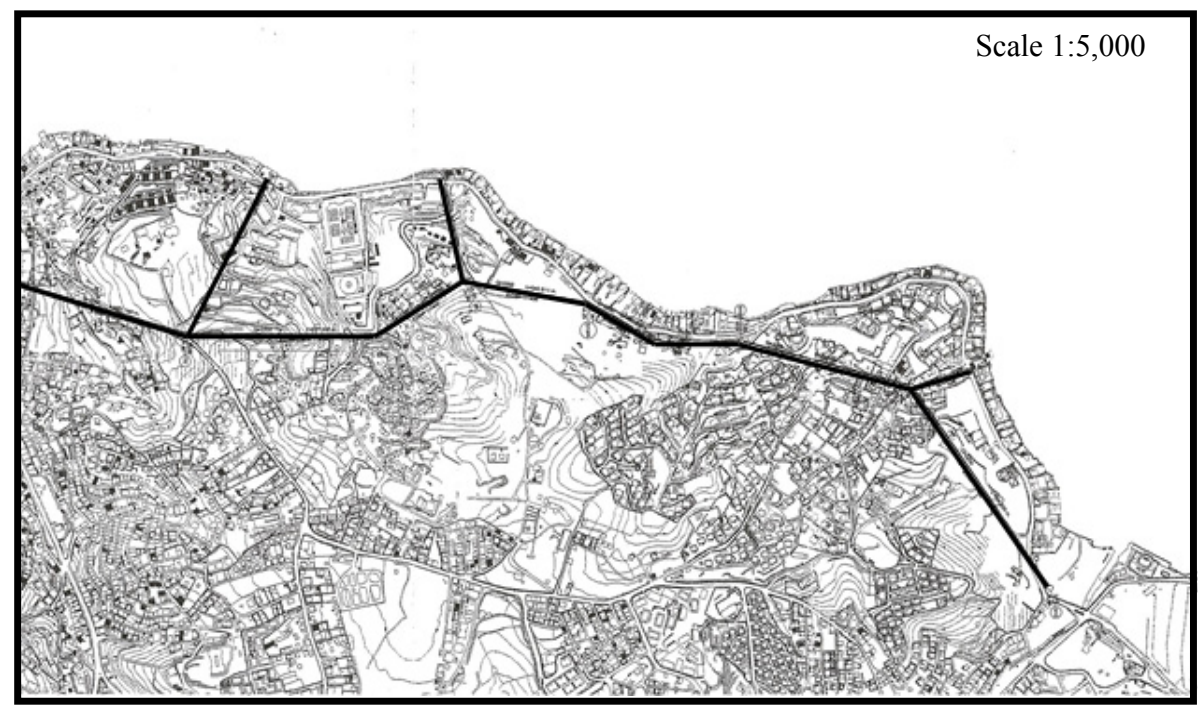

Fig. 1 The wastewater tunnel route [7].

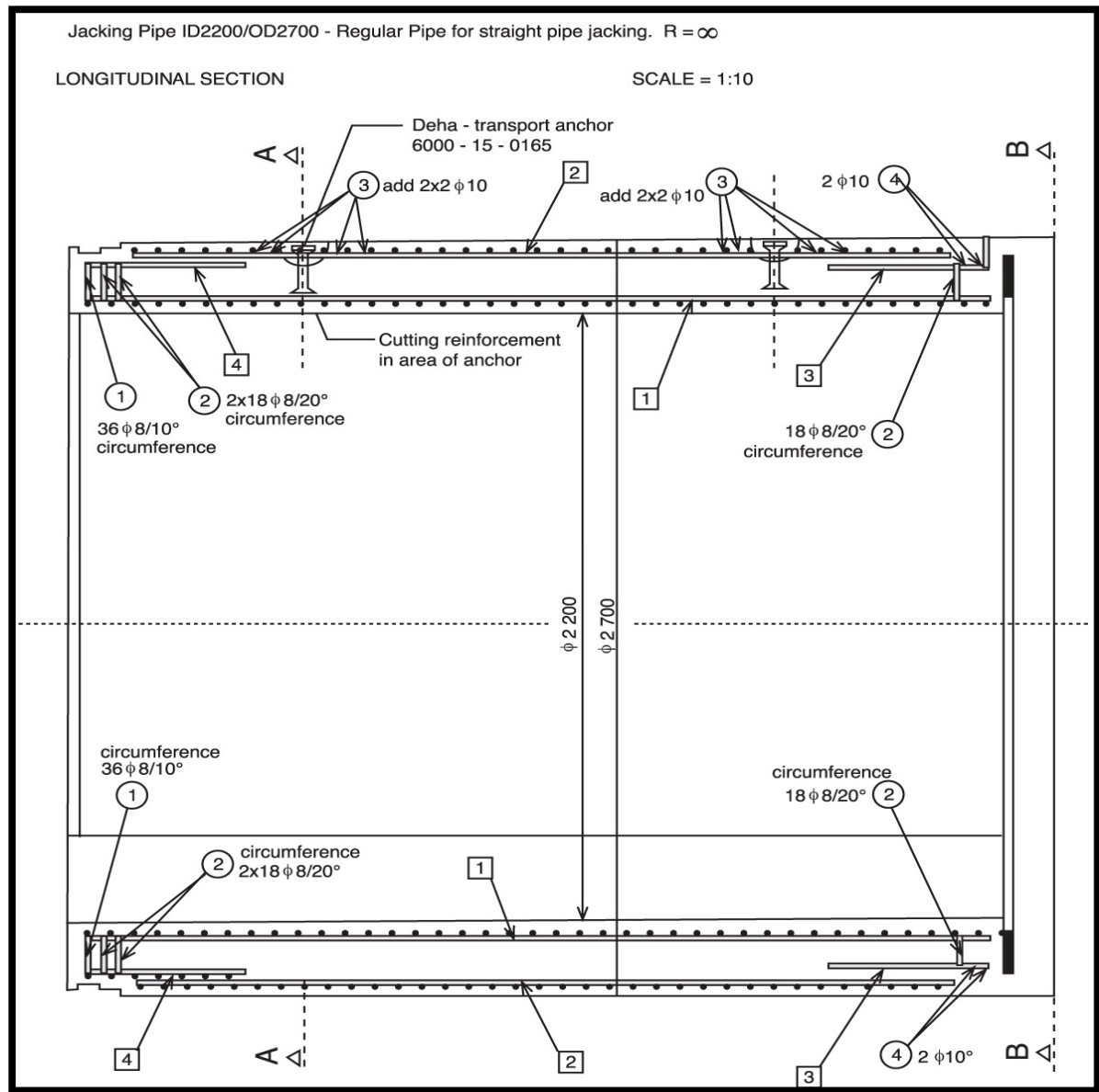

Fig. 2 Longitudinal section view of the wastewater tunnel. 


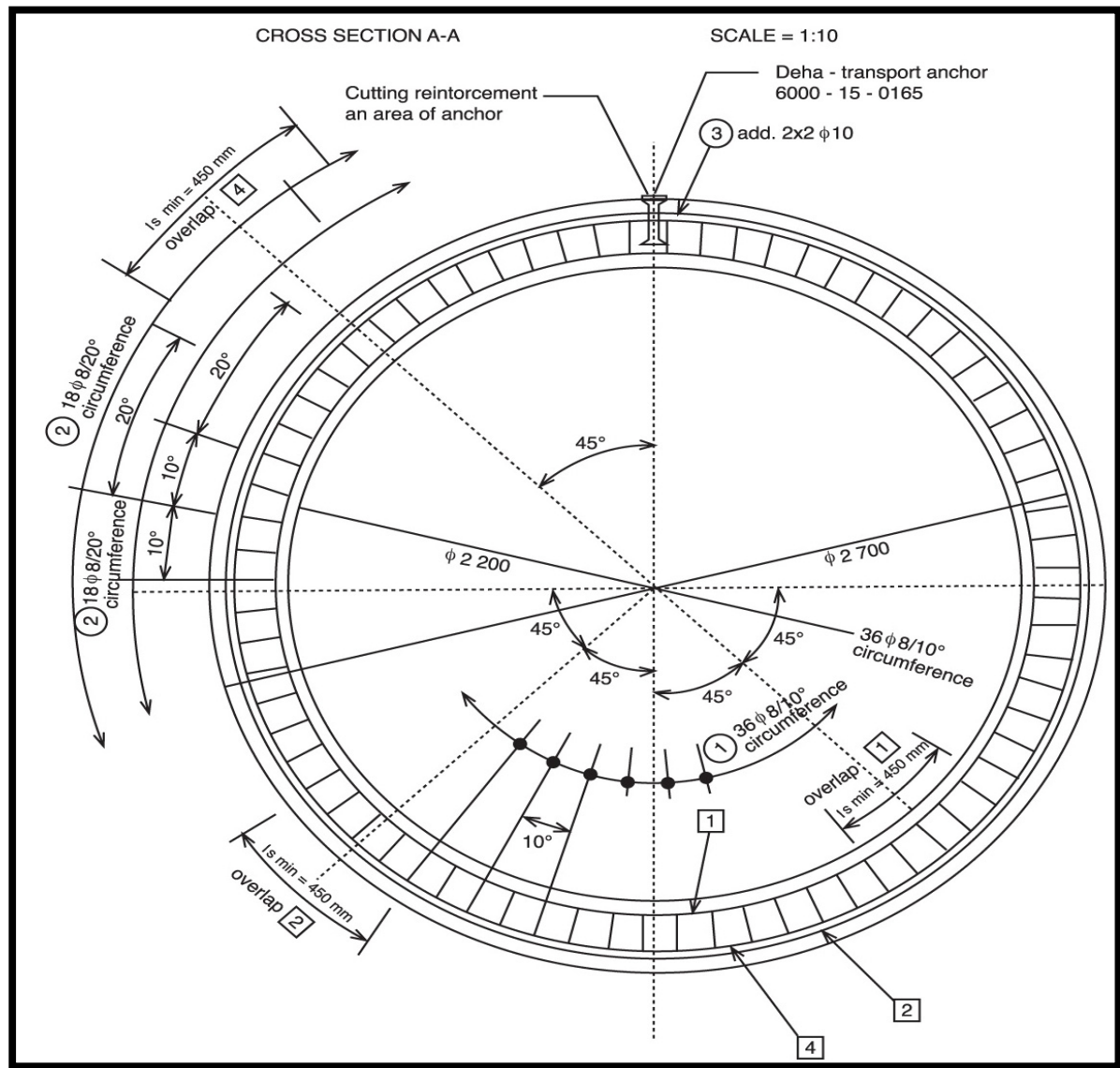

Fig. 3 Cross section view of the wastewater tunnel.

Table 3 The depths of the underground water.

\begin{tabular}{llc}
\hline Boring No. & $\begin{array}{l}\text { Depth of ground } \\
\text { water }(\mathrm{m})\end{array}$ & $\begin{array}{l}\text { Ground water } \\
\text { grade }(\mathrm{m})\end{array}$ \\
\hline S1 & 6.50 & +2.00 \\
S2 & 3.50 & +3.00 \\
S3 & 6.40 & +30.10 \\
S4 & 7.00 & +0.50 \\
\hline
\end{tabular}

Table 4 Technical properties of EPB/slurry TBM AVN 2200 AB [8].

\begin{tabular}{ll}
\hline Diameter of the cutter head & $2.775 \mathrm{~m}$ \\
\hline Power on the cutter head & $160 \mathrm{~kW}(217.6 \mathrm{HP})$ \\
Mechanical efficiency & $85 \%$ \\
Pipe-Jacking main station and Interjack & $13,600 \mathrm{kN}$ \\
Force (Max.) 500 Bar & $2.7 \mathrm{~m}$ \\
Outer diameter of the pipe installed & $6.048 \mathrm{~m}^{2}$ \\
\hline
\end{tabular}

carried out in the research area [7].

\subsection{The Properties of TBM (Tunnel Boring Machine)}

The technical information of the TBM and pipe jacking used in the underground water tunnel under investigation is given in Table 4.

\section{Determination of the Level of the Damage Originating from an Earthquake for the Wastewater Tunnel in Question}

In the underground structures, especially in the tunnels, one of the main factors used in determination of the damages originating from an earthquake is the maximum horizontal ground value [8]. Firstly, this value would be determined by using different acceleration reduction equations. The level of the damage, on the other hand, would be identified by using the curves on horizontal round acceleration-tunnel damages given in the literature. According to the ground investigation report [7], prepared for the tunnel in question, 4,300 $\mathrm{m}$ of the ground of the tunnel was determined as basic rock. Only $250 \mathrm{~m}$ of the ground is natural ground and/or artificial ground. The investigations point out that the 
ground base of the ground is $A$ type and the class of the local ground is $Z 1$. It is advised that periods of the spectrum characteristics should be taken as $T_{A}=$ 0.10 and $T_{B}=0.30$. For the valley passage, the base of the ground belongs to group $D$ and the class of the local ground is $Z 4$. For this, it is considered that spectrum characteristics values of $T_{A}=0.20$ and $T_{B}=$ 0.90 are suitable. For the weakest part of the tunnel, calculations in determination of the level of the damage are carried out as follows. The vertical distance of the wastewater tunnel to the fault, $D$ is equal to $48 \mathrm{~km}$. The depth of the tunnel axis, $H$ was taken as $30 \mathrm{~m}$ for the horizontal distance of $4,190 \mathrm{~m}$. By considering these assumptions:

(1) If the maximum horizontal ground acceleration value is calculated by using the equation given in Ref. [9]:

$$
\begin{aligned}
& \log a_{y}=3.287+0.503\left(M_{w}-6\right)-0.079\left(M_{w}-6\right)^{2}- \\
& -1.1177 \cdot \log \sqrt{D^{2}+(14.82)^{2}}+ \\
& +0.141 \cdot Z_{1}+0.331 \cdot Z_{2}+P \cdot \sigma_{\left(\log a_{y}\right)}
\end{aligned}
$$

Considering the conditions of the ground, $Z 1$ and $Z 2$ were taken as 1 and 0, respectively. Meanwhile, for $84 \%$ safety factor, $P$ was taken as 1 . If moment magnitude, $M_{w}$ is taken 7.4.

By using these assumptions;

$$
\begin{aligned}
& \log a_{y}=3.287+0.503(7.4-6)-0.079(7.4-6)^{2}- \\
& -1.1177 \cdot \log \sqrt{48^{2}+(14.82)^{2}}+0.141 \cdot 1 \\
& \log a_{y}=2.076 \rightarrow a_{y 1}=119.16 \mathrm{~cm} / \mathrm{sn}^{2} \\
& \quad a_{y 1}=119 / 981=0.122 \mathrm{~g}
\end{aligned}
$$

(2) If maximum horizontal ground acceleration value is calculated by using the equations given by Arıoglu and Yılmaz [10];

$$
\begin{aligned}
& \log a_{y}=2.080+0.214 M_{s}-1.049 \cdot \log R+ \\
& +C_{S} \cdot Z_{S}+C_{Y} \cdot Z_{Y}+P \cdot \sigma \\
R= & \sqrt{D^{2}+h_{f}{ }^{2}} \rightarrow R=\sqrt{48^{2}+7.27^{2}}=48.547 \mathrm{~km}
\end{aligned}
$$

Surface-wave magnitude, $M_{s}=7.4, V_{s 30} \leq 360 \mathrm{~m} / \mathrm{s}$ in soft grounds and if ground factor is taken as $Z_{y}=1$, $C_{y}=0.085$; $\log a_{v}=2.080+0.214 \cdot 7.4-1.049 \cdot \log (48.547)+0.085 \cdot 1$

It is found that $\log a_{y 2}=1.9798 \rightarrow a_{y 2}=95.46$ $\mathrm{cm} / \mathrm{s}^{2}=0.097 \mathrm{~g}$.

(3) When another equation given by Arığlu and Y1lmaz [10] is used:

$$
\begin{aligned}
& \log a_{y}=-0.312+0.229 \cdot M_{w}- \\
& -0.779 \cdot \log \left(D^{2}+5.57^{2}\right)^{0.5}-0.371 \cdot \log V_{s}
\end{aligned}
$$

including $V_{s}=$ wave propagation velocity;

$$
\begin{gathered}
V_{s}=107.6 \cdot N^{0.36}=107.6 \cdot 6^{0.36} \Rightarrow \\
V_{s}=205.1 \mathrm{~m} / \mathrm{s} \text { is found. }
\end{gathered}
$$

If $M_{w}=7.4, D=48 \mathrm{~km}, V_{s}=205.1 \mathrm{~m} / \mathrm{s}$ values are put into Eq. (3), maximum horizontal acceleration value,

$$
\begin{aligned}
& \log a_{y}=-0.312+0.229 \cdot 7.4- \\
& -0.779 \cdot \log \left(48^{2}+5.57^{2}\right)^{0.5}-0.371 \cdot \log 205.1 \\
& \log a_{y}=-0.312+0.229 \cdot 7.4-1.3119-0.8577
\end{aligned}
$$

If $\log a_{y}=-0.7870$, then it was calculated that $a_{y 3}=$ $0.163 \mathrm{~g}$.

(4) If the same calculation was performed by using Eq. (4):

$$
\begin{aligned}
& \ln a_{y}=0.393+0.576\left(M_{w}-6\right)-0.107\left(M_{w}-6\right)^{2} \\
& -0.899 \cdot \ln R-0.200 \cdot \ln \left(V_{s 30} / 1112\right)+P \cdot \sigma(\ln a y)
\end{aligned}
$$

If $D=48 \mathrm{~km}$ and $h_{f}=6.91 \mathrm{~km}$ are taken, $R=\sqrt{D^{2}+h_{f}^{2}} \rightarrow R=\sqrt{48^{2}+6.91^{2}}=48.5 \mathrm{~km}$.

$$
\begin{aligned}
& \ln a_{y}=0.393+0.576(7.4-6)-0.107(7.4-6)^{2}- \\
& -0.899 \cdot \ln (48.5)-0.200 \cdot \ln (205.1 / 1112) \\
& \ln a_{y}=0.393+0.8064-0.20972-3.4895-0.338
\end{aligned}
$$

It is found that $\ln a_{y}=-2.1617 \rightarrow a_{y 4}=0.115 \mathrm{~g}$.

(5) If the arithmetic average value of this maximum horizontal acceleration is calculated,

$$
\begin{gathered}
a_{y}=\left(a_{y 1}+a_{y 2}+a_{y 3}+a_{y 4}\right) \\
=0.122 \mathrm{~g}+0.0970 \mathrm{~g}+0.163 \mathrm{~g}+0.115 \mathrm{~g}) / 4=0.124 \mathrm{~g}
\end{gathered}
$$

By considering $a_{y}=0.124 \mathrm{~g}, H=30 \mathrm{~m}$ and $50 \%$ safety factor, examination of the maximum horizontal ground acceleration-depth relation given in Fig. 4 yields that light damages can occur in the wastewater tunnel, in question. 


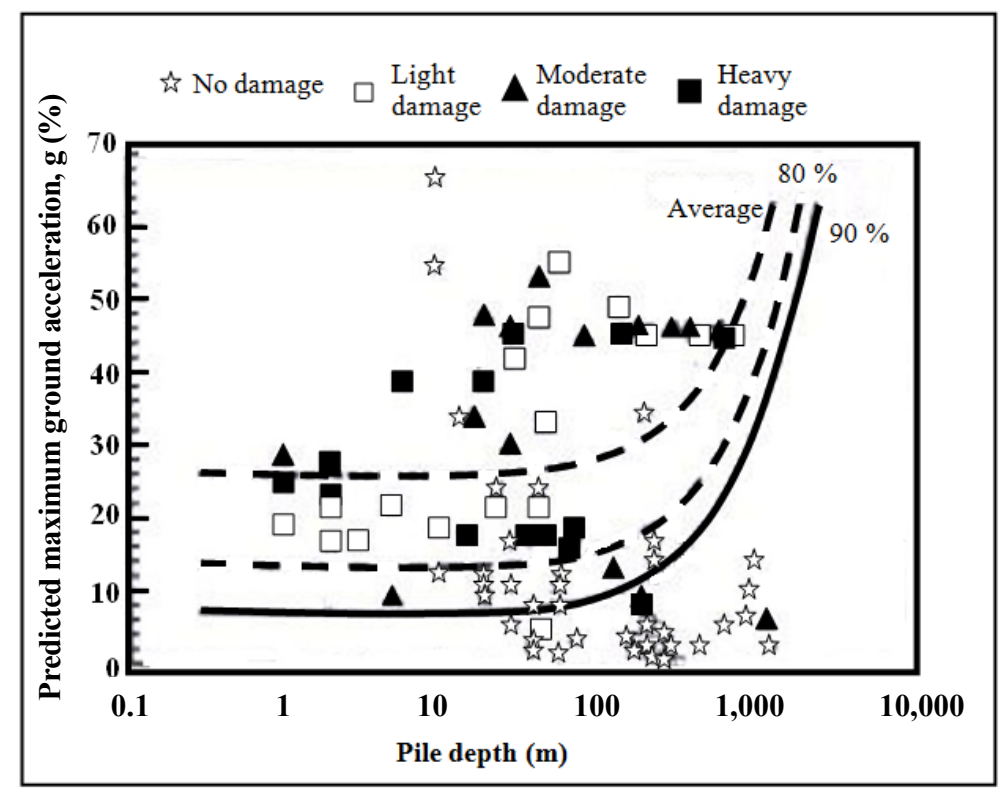

Fig. 4 Maximum ground horizontal acceleration (measured above the ground/calculated)—depth of tunnel damage relation [11].

If the Fig. 4 is examined, it can be clearly seen that the level of damage caused by the earthquake decreases with increasing depth of the tunnel.

\section{Conclusions}

The knowledge of the behavior of the existing underground structures is highly important to take precautions for the possible damages. It is vital to know the response of these structures against earthquake effects so that the possible damage levels can be predicted in advance. After an earthquake, not only damages affecting the daily life but also damages resulting in significant economic losses and conditions that can threat the public health can be minimized.

The depth at which the tunnel construction is carried out, the properties of the ground and the method of tunnel construction are factors affective to the level of the damage. For this reason, in the project design and application stages of such constructions, these points must be taken in consideration. In order to reduce the seismic damages in wastewater tunnels, it is necessary to take precautions such as the use of mobile junctions, isolation of the tunnel line from the ground motions etc..

\section{References}

[1] Ö. Yüzügüllü, G. Birgören, The behavior of the infrastructure in earthquakes and damages formed, in: Fifth National Conference on Earthquake Engineering, Istanbul, Turkey, May 26-30, 2003.

[2] G.N. Owen, R.E. Scholl, Earthquake Engineering of Large Underground Structures, Report no. FHWA/RD-80/195, U.S. Department of Transportation, Federal Highway Administration and National Science Foundation, 1981.

[3] T. Çağatay, The structural behavior of the wastewater structures under the effect of earthquake and an example study, M.Sc. Thesis, Istanbul University, Institute of Science, Istanbul, 2010.

[4] E.C. Cüceoglu, The seismic design of the underground structures, M.Sc. Thesis, Institute of Science and Technology, Istanbul, 2006.

[5] C.M. John, T.F. Zahrah, A seismic design of underground structures, Tunnelling and Underground Space Technology 2 (2) (1987) 165-197.

[6] Ö. Yüzügüllü, K. Uğurlu, The seismic performance of the Istanbul's wastewater and water network, in: Earthquake Symposium, Kocaeli, Turkey, Mar. 23-25, 2003, pp. 1376-1383.

[7] Genson Ltd. Co., ISKI Additional Geotechnical report, Report No. 2003/196, IST, 2003.

[8] A. Kahriman, T. Çoşgun, M. Akgül, Expert's report: 2006-30, Istanbul, 2006.

[9] C. Özbey, A. Sarı, A. Manuel, M. Erdik, Y. Fahjan, Empirical strong ground motion attenuation relations for 
northwest Turkey, in: Fifth National Conference on Earthquake Engineering, Istanbul, Turkey, May 26-30, 2003.

[10] E. Arıoğlu, A.O. Yılmaz, Seismic analysis of the tunnel gallery with solved problems, Technical Thesis, Istanbul
Branch of Turkish Chamber of Mining Engineers, 2006.

[11] S. Sharma, W.R. Judd, Underground opening damage from earthquakes, Engineering Geology 30 (3-4) (1991) 263-276. 